\title{
RECONSTRUÇÃO IDENTITÁRIA NA LITERATURA AFRO-BRASILEIRA DE CONCEIÇÃO EVARISTO
}

\author{
Nara Rúbia Gomes Duarte Xavier ${ }^{1}$
}

\begin{abstract}
RESUMO: este artigo busca discutir as nuances da construção identitária da mulher negra, a partir da personagem Maria-Nova do romance Becos da memória de Conceição Evaristo. Tal personagem apresenta, por meio de sua vivência, a história de um coletivo, o qual é permeado pela violência de classe e de gênero. Por meio dessa narrativa, elementos como gênero, raça, etnia e memória surgem como questões relevantes que promovem ao leitor uma reflexão sobre a realidade social brasileira. A temática é abordada por meio do recurso da memória, pelo qual a autora constitui uma escrita que identifica estrias sociais e aponta os empecilhos presentes na busca pela emancipação da mulher negra. Subsidiado por estudos teóricos e bibliográficos, este estudo traz uma análise do romance de Evaristo, refletindo sobre mulher negra ser testemunha de sua situação social. Nesse sentido, destaca-se que a literatura, em Conceição Evaristo, não apenas mantém elos com a memória coletiva e cultural, como demanda denúncia e conscientização social.
\end{abstract}

PALAVRAS-CHAVE: Mulher negra; Identidade; Memória; Conceição Evaristo

ABSTRACT: this article tries to discuss the nuances of the black woman identity construction, from the Maria-Nova character of the novel Becos da memória by Conceição Evaristo. This character presents, through his experience, the history of a collective, which is permeated by class and gender violence. Through this narrative, elements such as gender, race, ethnicity and memory emerge as relevant issues that promote the reader a reflection on Brazilian social reality. The theme is approached through the use of memory, through which the author constitutes a writing that identifies social gaps and points out the obstacles present in the search for the emancipation of the black woman. Supported by theoretical and bibliographic studies, this study brings an analysis of Evaristo's novel, reflecting on black women being witnesses of their social situation. In this sense, it is emphasized that in Conceição Evaristo, literature not only maintains links with collective and cultural memory, but also demands denunciation and social awareness.

KEYWORDS: Black woman; Identity; Memory; Conceição Evaristo

\section{INTRODUÇÃO}

A literatura brasileira no decorrer de sua formação vem passando por alterações significativas em seu corpus bem como em seus métodos de criação e seus pressupostos críticoteóricos, nos quais se alicerçam os sujeitos sociais para demandar novas discursividades. Assim, pressupõe uma gama literária ampla numerosa e múltipla, como aponta Rezende (2008).

Dessa forma, contemplar a literatura contemporânea em estudos e análises é migrar de modelos estéticos definidos e estruturados para uma seara aberta a uma diversidade de formas de produção em que se encontram vozes, estilos e linguagens variados. Nesse contexto encontra-se a literatura afro-brasileira que, mesmo sendo um termo em construção, como afirma

\footnotetext{
${ }^{1}$ Mestra em Educação, Linguagem e Tecnologias - Universidade Estadual de Goiás - UEG/GO. Aluna especial do Programa de Pós-graduação Letras Linguística - Doutorado - Faculdade de Letras - Universidade Federal de Goiás - UFG/GO. E-mail: naraestadual@gmail.com
} 
Duarte (2011, p. 375-385), já indicou produções no século XVIII com Domingos Caldas Barbosa. Essa literatura questiona a concepção de uma identidade nacional vista como única, homogênea e coesa, pois o que se verifica são escritas híbridas e plurais, resultantes de fatos históricos, sociais e culturais.

As alterações não se restringiram apenas as formas de escrever e as temáticas. Autores e leitores também passaram por modificações em suas estruturas; esses perderam sua "nitidez e homogeneidade" (MORICONI, 2002, s/p). Os autores desenvolveram seus próprios estilos e projetos individuais; já não ocupam o mesmo lugar de antes onde controlava todo o processo de criação literária. A imagem do escritor como alguém que possui o domínio sobre a escrita não se faz presente na literatura contemporânea. Esse espaço é dividido com outras estruturas como narrador, personagens e leitor. Assim, a totalidade da arte não é possível (LADDAGA, 2010). Ademais, vozes consideradas ilegítimas, não autorizadas, como as de negros, pobres e outras minorias surgem como sujeitos protagonistas que se fazem ouvir e que produzem nessa vertente literária.

Nesse sentido, ressalta-se a necessidade de, segundo Bernd

[...] questionar a forma como foi escrita a história do negro no Brasil, assim como sua contribuição nos domínios literários, e esperar que o surgimento de uma anti-história e de formas de contraliteratura possam tirar da clandestinidade muitos fatos que, por ora, a cultura triunfante mascara (BERND, 1988, p. 18).

Corroborando essa ideia, é necessário abordar o sujeito negro como "universo humano, social, cultural e artístico de que se nutre essa literatura (afro-brasileira) (IANNI, 2011, p.184, acréscimos nossos).

Assim, Conceição Evaristo brinda o leitor contemporâneo com uma produção ímpar e particular que associa cultura, ressignificação de identidades e enunciações negras a partir de um trabalho específico com a linguagem em que se contempla a oralidade e a memória. O objetivo dessa escrita é evidenciar como a escritora, em Becos da memória (2017), leva o leitor a refletir sobre o lugar de representação para o qual os negros, principalmente, a mulher está relegada. Pode-se afirmar que a autora traz uma produção com o intuito de alcançar a presença e a autoafirmação do negro em um caminho que visa restabelecer uma história diferente do que tem sido contada por uma cultura homogeneizante.

O romance é permeado por uma dramaticidade a qual tem por objetivo trazer para a literatura o dia a dia daqueles que estão submetidos à violência em seus diversos matizes. Becos e barracos formam o contexto da obra; são fragmentos que buscam associar denúncia social e 
lirismo. Além disso, Conceição Evaristo traz no livro traços biográficos, os quais constroem a personagem protagonista Maria-Nova. Mescla-se, desta forma, uma escrita de si com o romance, o universal com o indivíduo, pois, para autora, pensar em si é pensar no coletivo.

A constituição do enredo é realizada por meio de fragmentos e não por capítulos. São histórias de indivíduos e de famílias completas contadas e recontadas na perspectiva benjaminiana, valorizando a oralidade, a informalidade. Logo, tais fragmentos formam uma teia literária que estrutura todo o romance. Por meio de cada fragmento, oriundo de determinado beco ou barraco da favela, é possível conhecer uma história, uma vida, um indivíduo diferente. Nesse contexto, os menos favorecidos ganham voz por meio de Maria-Nova. Menina, mulher negra, pobre, moradora da favela, "passeia" pelas vielas e barracos apresentando ao leitor, por meio da memória e da oralidade, cada morador e suas respectivas lutas e dores. Dessa forma, ela integra as demais personagens, constituindo um sujeito autoral.

Assim, o romance busca trazer ao texto literário o silenciamento do negro na literatura e na cultura, o surgimento de sua voz e a construção de uma identidade negra, resultante de um modelo estético diaspórico. Abordam-se os espaços ocupados pelos negros na narrativa, os métodos e procedimentos utilizados pela narradora no intuito de contemplar a realidade afrodescendente e a memória como estratégia para relacionar a temática do romance aos conflitos e aos meios que os negros tinham como resistência. Com isso, observa-se um trabalho com aspectos relacionados ao gênero, à raça, à etnia e à memória, trazendo uma reflexão sobre a realidade social brasileira por meio de histórias e contextos específicos.

\section{MEMÓRIA E IDENTIDADE NEGRAS}

Conceição Evaristo trata-se de uma autora envolvida com a crítica social, com a ancestralidade cultural e com assuntos referentes à existência da mulher na sociedade. Logo, seu trabalho leva à reflexão da literatura como um exercício de alteridade.

Em Becos da memória (2017) encontra-se uma narração que privilegia e homenageia, de início, as pessoas que formaram os "becos" da memória, a qual se transforma em escrita. Assim, nas palavras da escritora, “[...] homens, mulheres, crianças que se amontoaram dentro de mim, como amontoados eram os barracos da minha favela" (EVARISTO, 2017, p. 17). A partir dessa abordagem, a narradora apresenta os personagens que serão resgatados para a constituição de sua identidade, pois a mesma será construída a partir das vozes e de outras identidades presentes no texto. 
Nesse contexto, o leitor depara-se com narrativas permeadas por dramaticidade em que a autora traz para a ficção a angústia e a apreensão do cotidiano de indivíduos que, constantemente, encontram-se sujeitos à violência em suas diversas ramificações. Tem-se um cenário construído por barracos, delegacias e becos; um ambiente no qual se encontram sujeitos excluídos socialmente como pobres, humilhados, ofendidos, mulheres e homens negros, demonstrando a composição da pobreza brasileira. Conceição Evaristo tira o negro da posição de invisibilidade social e cultural, pois a narradora negra toma a palavra, ou seja, a escrita apresenta-se por meio dela, como sujeito da enunciação, representando uma mudança da marginalização para o empoderamento.

O romance é construído pelos elementos que Conceição Evaristo denominou de escrevivência. Um processo literário que surge da vida real, da vivência do dia a dia, que se torna ficção. Para Ferreira (2013), a escrevivência refere-se aos gritos africanos, contadores de histórias, necessitando, dessa maneira, da memória coletiva:

Nesse sentido, autora e personagem escrevem nossas antigas histórias, relatos africanos, que saem da boca dos gritos e se eternizam nos livros. Solução encontrada para se resolver a ameaça do esquecimento, aquele provocado pelo sequestro, pela viagem, pela distância, pela dor, pelo banzo. Solução para a invisibilidade. Aquela provocada pelo silêncio imposto, pela vontade negada, pela História que se registrou, pelos terreiros incendiados, pela idade avançada, pela ordem, pelo progresso (FERREIRA, 2013, p. 47).

Na escrevivência encontram-se particularidades relativas ao corpo, à condição e à experiência humanas. Nesse sentido, é uma escrita que parte do contexto do negro (da mulher negra), permeada por questões de gênero, raça e classe social. Logo, Conceição Evaristo ficcionaliza as memórias, ou seja, estas "vivências", particularizando a sua obra, contemplando discursos entendidos, ao longo da história, como ilegítimos e marginais, por estarem inseridos em uma classe e em um espaço relegados à obediência e à submissão.

No contexto da favela, têm-se histórias vivenciadas em becos os quais, concomitantemente, apresentam-se como diversos, iguais, tortuosos e múltiplos. Nessa concepção de narração, a literatura, sob um paradigma oficial de produção, em que se encontravam escritores brancos, burgueses e heterossexuais, passa a dividir espaço com novos projetos literários em que se aborda a realidade brasileira a partir de pontos de vista marginais ou periféricos; personagens pobres e favelados que a sociedade e a literatura eurocêntricas visam esconder. Nesse sentido, "a identidade é reivindicada a partir de uma posição de marginalidade ou em uma tentativa de ganhar o centro. " (BHABHA, 2005, p. 247) 
Ao contemplar a questão da identidade, observa-se que o mesmo não se apresenta como um elemento intacto e irredutível, pois os personagens possuem suas identidades formadas por meio da fragmentação do sujeito em um processo de hibridização, corroborando a concepção de que a identidade de um indivíduo está sempre em formação. Trata-se de algo aberto, inacabado e fragmentado, pois o homem contemporâneo "está se tornando fragmentado; composto não de uma única, mas de várias identidades, algumas vezes contraditórias ou não resolvidas " (HALL, 2006, p. 12). Nesse sentido, nota-se um uma pessoa incompleta e híbrida, cuja identidade está em constante formação.

É por meio da memória de Maria-Nova que se presencia uma discussão acerca dessa identidade, contemplando a dificuldade em ser, estar e viver em uma sociedade como um sujeito negro. A memória configura-se como guia condutora da narrativa, despertando a atenção por ser um recurso que funde forma e conteúdo ao contemplar questões relativas à identidade e à cultura do negro. Ela permite um direcionamento do olhar para o coletivo, no sentido de resgatar o passado e isentar o sujeito do esquecimento em que a sociedade coloca o indivíduo negro.

Com efeito, ao contemplar a questão da identidade, observa-se que a mesma não se apresenta como um elemento intacto e irredutível, pois os personagens possuem suas identidades formadas por meio da fragmentação do sujeito em um processo de hibridização, corroborando a concepção de que a identidade de um indivíduo está sempre em formação. Trata-se de algo aberto, inacabado e fragmentado, pois o homem contemporâneo, já uma vez considerado como pertencente a uma identidade estável "está se tornando fragmentado; composto não de uma única, mas de várias identidades, algumas vezes contraditórias ou não resolvidas. ” (HALL, 2015, p. 12). Trata-se de uma identidade subsidiada em uma concepção sociológica e não iluminista, constituída a partir da“ interação entre o eu e a sociedade” (HALL, 2015. p. 12). A identidade na vertente sociológica contempla as contribuições sociais para a sua formação, diferentemente da identidade iluminista, a qual afirmava que o sujeito já nascia uma identidade e com ele se desenvolvia.

No romance, as memórias surgem de maneira fragmentada, representando as interações sociais que ela mantém, e prezando o tempo psicológico da narradora; há assim um movimento de idas e vindas proporcionado pelas lembranças de Maria-Nova. E mesmo o leitor encontrando uma sequência cronológica, ele depara-se com essas voltas, o que proporciona ao romance um trançado de vivências e experiências.

Essas vivências podem ser observadas na reprodução da fala do personagem Tio Totó, pois são apresentadas as aflições, as experiências pessoais e as dos companheiros de Tio Totó. 
Quando Tio Totó se entendeu por gente, ele já estava em Tombos de Carangola. Sabia que não nascera ali, como também ali não nasceram seus pais. Estavam todos na labuta da roça, da capina. Sabia que seus pais eram escravos e que ele já nascera na "Lei do Ventre Livre". Que diferença fazia? Seus pais não escolheram aquela vida e nem ele. (EVARISTO, 2017, p. 18-19 - destaques da autora).

A partir desse relato, Tio Totó constrói sua identidade e deixa indícios para que MariaNova também construa a sua, entendendo os percursos pelos quais seus antepassados passaram. As histórias dela, do Tio e a dos outros moradores se misturavam formando uma só. "Tio Totó não entendia que os seus noventa e tantos anos eram necessários aos quase quinze de Mariinha" (EVARISTO, 2017, p.76). Seus relatos eram ouvidos por Maria-Nova e ao compreendê-los, compreendia o que se passava ao seu redor.

Assim, Maria-Nova, ao ouvir as narrações e reproduzi-las aos leitores, posiciona-se em uma postura benjaminiana, cuja particularidade contempla a oralidade, o contar e o ouvir histórias; uma vertente que favorece o fragmento em detrimento da totalidade e a alegoria sobre o símbolo (BENJAMIM, 1993). Destarte, Maria-Nova exerce um relevante papel na narrativa; ela ouve e busca os relatos para apresentá-los ao leitor; e ao ouvir as histórias, a protagonista passa a vivenciar os sentimentos de quem os narra, reiterando o sujeito sociológico de Stuart Hall (2015).

Nessa relação, o passado é utilizado para a construção do presente. As identidades, assim, encontram-se em desenvolvimento, dentro do processo de construção do discurso. Maria-Nova usa de seu conhecimento, de suas lembranças e de sua oralidade para dar voz às outras pessoas da favela; para mostrar o seu desejo por uma vida melhor: "Um dia não se sabia como ela haveria de contar tudo aquilo ali. Contar as histórias dela e dos outros. Por isso ela ouvia tudo tão atentamente. Não perdia nada. ” (EVARISTO, 2017, p. 36)

Sobre a formação dessa identidade híbrida, constituída a partir das vozes de outrem de tempos passados, Delcastangnè (2012, p. 80, aspas da autora) afirma que em romances contemporâneos podem-se encontrar personagens que "para confirmar sua existência, precisem 'organizar um passado"”. Maria-Nova utiliza-se do passado para se constituir como sujeito, encontrar e ocupar seu lugar na sociedade. O passado surge no texto como elemento basilar para a constituição de Maria-Nova, pois aproxima a história da narradora com a de seus antepassados em um processo de construção de consciência, a qual é fruto destas relações: presente e pretérito; Maria-Nova e antepassados. Logo, a forma como Maria-Nova interpreta e compreende o passado faz com que o presente seja moldado, interferindo em seu modo de agir e 
pensar. A convivência com outras pessoas da favela faz com que a personagem seja inserida na história e passe a ter seu próprio espaço, sua própria história.

Devido à formação identitária estar sempre em processo de construção, em um fazer e refazer constantes, não há, por sua vez, uma cultura íntegra, única e pura; e sim uma cultura híbrida composta por composições plurais e multiculturais. Sobre a presença de hibridismo na constituição identitária em Becos da memória (2017), observa-se que Tio Totó apega-se a elementos religiosos tanto de origem africana quanto europeia. Nessa atitude, é possível perceber indícios de resistência diante do processo de apagamento de sua cultura em detrimento da europeia. Tem-se assim uma identidade que não é nem branca e nem negra e sim híbrida; formada por elementos africanos e europeus. Tal posicionamento pode ser visto em:

(...) Lembravam-se de deuses negros, reais, constantes e tão diferentes daquele Deus-Jesus de que tanto falavam os senhores e os padres (...). - É Miquilina, se agarra à menina Catita, eu me agarro aos trapos. Santa Bárbara há de nos ajudar! ... (EVARISTO, 2017, p. 20).

Depois, muitos anos depois, uma ferida apareceu na perna de Sinhô moço, na mesma perna, no mesmo lugar. De nada valeu todo tratamento, todo cuidado. Nem médicos, nem garrafadas, nem rezas de pretos-velhos. A ferida sangrava, fedia e comia a perna do Sinhô moço. Os negros diziam que era castigo de Deus. E ficavam felizes, porque tinham um Deus que se vingava por eles e que um dia lhes daria o reino do céu. (EVARISTO, 2017, p. 59).

Assim, a construção da identidade negra no romance é apresentada por meio das atitudes subjetivas e coletivas dos personagens em manterem costumes africanos. Os personagens mesclam as matrizes religiosas: "garrafadas" e "pretos velhos" constituem-se elementos da religião africana; e o "Deus que se vingava por eles e que um dia lhes daria o reino dos céus" faz parte da religião europeia. Vê-se, dessa forma, uma hibridização religiosa e cultural, pois o "sinhô branco" faz uso dos elementos religiosos africanos e os negros esperam no Deus dos brancos a sua salvação.

Além da religião, elementos como a música fazem-se presentes no romance. "O samba, o som, as alegrias voavam alto. Era preciso cantar. (...)” (EVARISTO, 2017, p. 72). Há, dessa forma, um enfraquecimento da cultura eurocêntrica, a qual perde espaço àqueles que foram silenciados e proibidos de manifestarem suas crenças e hábitos culturais ao longo da história, de forma mais específica, no período da escravatura. Desta forma, faz-se importante conservar a cultura afro-brasileira e, ao mesmo tempo, apresentar uma releitura da História, transmudando a concepção de que "civilização é associada ao mundo branco e barbárie ao mundo negro" (BERND, 1988, p. 42). Vozes negras mesclam-se às ditas oficiais. As margens aglutinam-se ao 
centro em um processo de rasura e apagamento, construindo outros centros. O que era visto como imutável e estável passa por um processo de fragmentação; uma estética diaspórica. Temse, desta forma, discursos heterogêneos, identidades híbridas que se completam; uma cultural plural.

$\mathrm{Na}$ busca por manter as particularidades da cultura negra, os personagens, moradores da favela, incentivam a formação de novas células familiares; e destas, surgem os filhos cujos nomes, elementos básicos de identidade, são aspectos híbridos na história. Maria, nome de origem portuguesa e Ilíada, grega:

$\mathrm{O}$ homem velho $\mathrm{e}$ o homem moço foram a caminho. $\mathrm{O}$ velho calado, o moço mudo. $\mathrm{O}$ homem moço comprou um pedaço de terra, passaram a lavrar o que era de seus, pai e filho. A vida seguia calma, boa, Luís vivia a cismar coisas, a falar sozinho. O pai olhava o filho, o filho olhava o pai, os dois estavam sozinhos. O pai queria tanto que o filho casasse, tivesse mulher e filhos, se multiplicasse, continuasse a raça. Luisão da Serra cumpriu os desejos do pai. Casaria. Uma negra calma haveria de ser a bonança, a paz, a lucidez de sua loucura. Teria filhos: Maria, Tatão, Natividade, Ilíada e Joana. (EVARISTO, 2017, p. 34-5).

Perante a essa construção identitária híbrida, fica claro na obra que a autora não quer impor uma ou outra cultura como melhor ou pior. Conceição Evaristo busca apresentar ao leitor que a identidade do povo brasileiro é composta por uma aglutinação e elementos africanos e europeus e que ambos são relevantes ao indivíduo. No entanto, ela nega paradigmas e estereótipos de passividade e submissão atribuídos ao negro, por uma parcela da sociedade, a qual se apresentava como detentora de uma identidade legítima e única.

\section{MARIA-NOVA: MULER NEGRA, SIM SENHOR!}

Ao produzir suas escritas, Evaristo acentua os problemas identitários das pessoas afrodescendentes com o objetivo de alcançar afirmação em contextos os quais excluem e mascaram o preconceito de cor e gênero. Em Becos da memória (2017), a autora produz uma narração em que ela se assemelha à Maria-Nova. Seria uma relação de espelhamento entre ela e a narradora, a qual representa as ações da escritora. Nesse sentido, as várias vozes presentes no romance são uma forma de Evaristo combater de maneira coletiva os paradigmas instituídos pela cultura eurocêntrica, construindo, dessa forma, a identidade de Maria-Nova e, consequentemente, a sua identidade. O negro, sob essa vertente, produz e escreve a sua própria história, apresentando suas perspectivas e questionamentos sobre a realidade. 
A personagem surge como um duplo da escritora; como uma porta-voz dos moradores negros da favela, representando e apontando dificuldades, abusos, angústias, medos e atos discriminatórios presentes. O próprio espaço, a favela situada no "morro do Pindura Saia", associa-se semelhantemente ao da infância de Evaristo. Nota-se com esse duplo uma relação de verossimilhança, de um novo realismo, que traz a experiência e o retorno do autor para dentro da narrativa. Sobre isso, Schollhammer (2011, p. 54) comenta que os escritores contemporâneos, os "novos realistas" buscam apresentar a realidade por outros meios, que não se pretende ser mimética nem representativa. Trata-se de um novo realismo que almeja "relacionar a literatura e a arte com a realidade social e cultural da qual emerge, incorporando essa realidade esteticamente dentro da obra e situando a própria produção artística como força transformadora." (SCHOLLHAMMER, 2011, p. 54)

A autora, por meio da narradora, apresenta orgulho em relação à cor negra de seu povo. E essa atitude pode ser vista como um ato de resistência, pois, aos negros, ao longo da história, foi destinada uma posição subalterna. No romance, por meio dessa demonstração de orgulho e espaço na narrativa, eles ganham visibilidade. É o que se nota em:

Ela disse se chamar Dora. Ela gostava muito do nome dela, aliás, Dora gostava muito de si própria. Ele disse se chamar Negro Alírio. Negro deveria ser apelido e Alírio o nome, mas ele dissera Negro Alírio. Gostou de ouvir a palavra negro pronunciada por um negro, pois o termo negro ela só ouvia na voz de branco, e só para xingar: negro safado, negro filha-da-puta, negro baderneiro e tantos defeitos mais! (EVARISTO, 2017, p. 95).

Tendo sua autoestima determinada, o sujeito negro, representado por Maria-Nova, tem sua identidade reconstruída. Ele escreve assim sua história; apresenta sua concepção de mundo e suas perspectivas acerca da realidade, não abdicando de seus objetivos perante a sociedade. Nesse sentido, há uma desconstrução de paradigmas: a ideia de negro como pessoa maleducada, feia e ignorante, sem lugar definido, cede espaço para uma visão positiva; um negro com cultura, personalidade, beleza e identidade ímpares. Tem-se, desta feita, em Becos da memória (2017), um exemplo de literatura negra, que se configura como uma literatura de resistência por demonstrar tal desconstrução de regras já interiorizadas e, concomitantemente, por construir uma identidade negra histórica e literária. Maria-Nova apresenta-se como símbolo resistência ao domínio eurocêntrico, pois se observam nela exemplos de recusa a modelos sociais, políticos e culturais. Posição de grande relevância por recuperar uma memória silenciada e negada ao longo da História. Assim, 
[...] a literatura negra brasileira configura-se como literatura de resistência, ou seja, a que constrói com a matéria a cultura africana que sobreviveu na América em presença da cultura europeia e indígena. A literatura utiliza o aporte dessa cultura resistente em uma produção que servirá para singularizar um grupo, fornecendo-lhe mitos, símbolos, valores, em suma, elementos que permitem a emergência de uma imagem positiva de si próprio. (BERND, 1987, p. 86 destaques da autora).

Ademais, a narradora também representa uma luta contra estereótipos racistas e preconceituosos, no que se refere ao gênero e à etnia. Ela, na figura de uma mulher negra, relembra a luta que as mulheres enfrentaram em busca de empoderamento. Se essa luta se apresentou árdua historicamente a esta classe, sabe-se que a mulher negra enfrentou percalços maiores, pois passou por processos de inferiorização piores, sendo discriminada não apenas por ser mulher, mas por ser negra, vista como mão de obra barata, escrava e objeto sexual. A ela, restando posições sociais inferiores, ocupando uma parcela mínima, quase irrisória, na participação política, social e cultural do país. No entanto, no romance em questão, a voz de Maria-Nova, uma voz feminina e negra, revela a voz de mulheres negras que têm sua posição social alterada. Deixa-se uma situação de submissão e subjugação para uma condição de autoafirmação e de transformação histórica.

A narradora é apresentada como uma mulher ativa, a qual busca compreender a sua realidade a partir de análises, relações e reflexões que ela faz ao aglutinar histórias passadas com seu presente e com sua perspectiva de futuro. Apresenta-se como questionadora da própria realidade.

\footnotetext{
$\mathrm{Na}$ semana anterior, a matéria estudada em História fora a "Libertação dos Escravos". Maria-Nova escutou as palavras da professora e leu o texto do livro. A professora já estava acostumada com as perguntas e com as constatações da menina. Esperou. Ela permaneceu quieta e arredia. A mestra perguntou-lhe que era o motivo de tamanho alheamento naquele dia. Maria-Nova levantou-se dizendo que, sobre escravos e libertação, ela teria pra contar muitas vidas. Que tomaria a aula toda e não sabia se era bem isso que a professora queria. Tinha para contar sobre uma senzala de que, hoje, seus moradores não estavam libertos, pois não tinham nenhuma condição de vida... (EVARISTO, 2017, p. 149-150).
}

Maria-Nova não aceitava as circunstâncias em que se encontrava e posicionava-se criticamente diante às problemáticas vividas em seu cotidiano. Assim, ao analisar a professora limitando a explanação de um conteúdo - escravidão - a uma visão homogeneizante e eurocêntrica, a narradora não se enxergava na situação superficial descrita; ela não via sentido e significação pertinentes no assunto, pois tanto ela como a autora viveram as explorações do branco; eram mulheres que se encontravam à própria sorte. 
E ciente das mazelas pelas quais seu povo passava, a protagonista soube decidir qual ferramenta utilizar para seguir adiante e denunciá-las, buscando formas de ser ouvida. Seria a escrita. Ela "haveria de narrar, de fazer soar, de soltar as vozes, os murmúrios, os silêncios, o grito abafado que existia, que era de cada um e de todos. Maria-Nova um dia escreveria a fala de seu povo" (EVARISTO, 2017, p. 177). Logo, a narradora crê que a escrita é um meio de resistência; e o contexto da favela é a sua inspiração, o seu ponto de partida, o mote para suas reflexões. Concepções de uma menina que, mesmo tendo que abandonar a escola, acredita que irá contar e mudar a história de seu povo.

No entanto, a narradora relata também a posição submissa e marginalizada de outras mulheres. Pessoas que sustentam sozinhas seus filhos e cuidam da casa; mulheres que sofrem agressões físicas, psicológicas e sexuais de seus cônjuges; mulheres que enfrentam diariamente o preconceito e a injustiça social; ou seja, dificuldades e desigualdades que buscam silenciá-las, fadando-as ao fracasso. Ao verbalizar as histórias dessas personagens femininas, a narradora passa a refletir acerca da própria existência humana. Uma existência que, muitas vezes, foi questionada no decorrer do romance. Pessoas como a esposa e filha de Fuinha, vítimas de violência doméstica e abuso sexual.

Nesse sentido, tem-se a presença de personagens femininas marcadas pela objetificação do ser humano e que se desenvolvem sem o uso de estereótipos, pois são mulheres que contextualizam em suas histórias a aproximação entre senzala e favela. Por sua vez, a favela tem grande relevância na narrativa, pois lembra um espaço de subordinação que o negro enfrentou no sistema escravocrata, o qual ainda fulgura na sociedade brasileira. No romance, favela e senzala são espaços semelhantes, pois materializam a condição de inferioridade e exclusão em que vivem os negros. Maria-Nova, ao refletir sobre a situação de seu povo na favela, "percebia a estreita relação de sentido entre a favela e a senzala, mas mais entristecia ao perceber que nos últimos tempos ali se vivia de pouco amor e muito ódio" (EVARISTO, 2017, p. 170)

De fato, a autora em Becos da memória afirma a existência de uma literatura negra permeada por seus próprios discursos e cultura, muitas vezes imbricados pelo hibridismo. No entanto, nessa literatura, encontra-se "o surgimento de um sujeito de enunciação no discurso poético, revelador de um processo de conscientização de ser negro entre brancos” (BERND, 1988, p. 48), ou seja, há um sujeito negro que não se encontra mais como objeto submisso entre os brancos, mas um sujeito enunciador de seu próprio discurso. Um sujeito que enfrenta as dificuldades presentes em meio a situações tristes, mas que não esquece e não desiste de um futuro melhor. 


\section{CONSIDERAÇÕES FINAIS}

A partir da concepção de que a ficção manifesta-se como necessidade de expressar um conteúdo essencial (LUCKÁS, 2000), a escrita de Becos da memória (2017) reiterou a cultura negra no Brasil. Partindo da realidade, a autora elabora a ficção, representando valores e ideais políticos, ideológicos e culturais, no sentido de humanizar e não estereotipar os personagens. Por meio da memória, a constituição da identidade negra é discutida, reiterando a concepção de o negro ser e estar no mundo como negro. Situações cotidianas são abordadas em um contexto específico: a favela. Logo, veem-se vidas precárias em que se identificam a fome, a violência física, sexual e psicológica, o alcoolismo, a falta de escolaridade e outros problemas. Estes levam o leitor a refletir sobre a condição em que o negro se encontra e já esteve um dia, quando obedecia a pressupostos eurocêntricos racistas e preconceituosos, de forma silenciosa, e aceitava a condição que lhes foi dada.

Nesse sentido, Conceição Evaristo mostra que esse negro submisso já não existe mais. Tem-se uma nova identidade, uma nova personalidade em uma estética diaspórica. São pessoas com concepções e cultura próprias. Uma cultura abordada, com maestria, pois a autora trouxe as particularidades dessa cultura sem, no entanto, colocá-la em posição exaltada. Desta forma, observa-se na narrativa a ideia de que não há dicotomias estabelecidas em referência à cultura afro-brasileira. Um trabalho estético narrativo realizado em um processo híbrido que demarca o contexto do romance.

Além disso, nota-se a aglutinação de elementos de culturas díspares, em uma vertente cuja especificidade principal é o excluído a construir a sua história, desfazendo paradigmas de um discurso já firmado socialmente. As minorias são assim abordadas e ouvidas; questiona-se a posição marginal e ilegítima a que estavam destinadas, admitindo uma concepção de ruptura. Desta forma, não há uma demarcação fixa e oficial do espaço. Tem-se uma escrita não subalterna que apresenta o negro lutando para sair da posição de marginalizado e mostra também a posição da mulher negra que vive em uma sociedade opressora. Assim, é possível notar que as identidades negra e branca estão sempre em formação, pois são fragmentadas e inacabadas. Não se tem assim uma identidade precisa e formada. No entanto, verifica-se a identificação do indivíduo negro, o qual está sempre marcado pela diferença, mas que não se comporta passiva e submissamente, mantendo-se em silêncio ou invisível perante a sociedade.

A partir de um trabalho e reiteração do passado, Conceição Evaristo mostra que este interfere no desenvolvimento dessa identidade que está em formação, pois o processo identitário 
de Maria-Nova, por exemplo, ocorre por meio da inserção da realidade cotidiana da comunidade nas recordações que ela apresenta ao leitor. Essa convivência e aproximação da protagonista com outras pessoas faz com que Maria-Nova aproxime-se de sua história com o objetivo de modificá-la.

\section{REFERÊCIAS}

BHABHA, Homi. K. O local da cultura. Belo Horizonte: Ed. UFMG, 2005.

BERND, Zilá. Negritude e literatura na América Latina. Porto Alegre: Mercado Aberto, 1987.

Introdução à literatura negra. São Paulo: Brasiliense, 1988.

BENJAMIN, Walter. Teses sobre a Filosofia da História. In: . Sobre arte, técnica, linguagem e política. Lisboa: Relógio D’Água, 1993.

CARNEIRO, Flávio. No país do presente: ficção brasileira no início do século XXI. Rio de Janeiro: Rocco, 2005.

DALCASTAGNÈ, Regina. Literatura Brasileira Contemporânea: um território contestado. Vinhedo: Editora Horizonte, 2012.

DUARTE, Eduardo de Assis. "Por um conceito de literatura afro-brasileira". IN: DUARTE, Eduardo de Assis; FONSECA, Maria Nazareth Soares. (Org.) Literatura e afrodescendência no Brasil: antologia crítica, v. 4. Belo Horizonte: UFMG, 2011, p. 375-403.

EVARISTO, Conceição. Becos da memória. 2. ed. Florianópolis: Mulheres, 2017.

FERREIRA, Amanda Crispim. Escrevivências, as lembranças afrofemininas como um lugar da memória afro-brasileira: Carolina Maria de Jesus, Conceição Evaristo e Geni Guimarães. 2013. 114p. Dissertação de mestrado (Mestrado em Letras - Estudos Literários), Universidade Federal de Minas Gerais, Minas Gerais.

HALL, Stuart. A identidade cultural na pós-modernidade. Rio de Janeiro: DP\&A, 2006.

IANNI, Octavio. Literatura e consciência. In: DUARTE, Eduardo de Assis; FONSECA, Maria Nazareth Soares. (Org.) Literatura e afrodescendência no Brasil: antologia crítica, v. 4. Belo Horizonte: UFMG, 2011, p. 183-198.

LUKÁCS, Georg. A teoria do romance. São Paulo: Duas Cidades; Ed. 34, 2000.

MORICONI, Italo. A literatura ainda vale? In: CONGRESSO INTERNACIONAL ABRALIC. 8, 2002. Belo Horizonte. Anais... Belo Horizonte: UFMG, 2002, s/p. 
REZENDE, Beatriz. A literatura brasileira na era da multiplicidade. In:

Contemporâneo. Expressões da Literatura Brasileira no século XXI. Rio de Janeiro: Casa da Palavra, 2008.

SHCOLLHAMER, Kark. Erik. Ficção brasileira contemporânea. Rio de Janeiro: Civilização Brasileira, 2011.

Recebido em: 15/02/2018

Aprovado em: 20/04/2018

Publicado em: 01/07/2018 